\title{
Advanced surface characterization of silver nanocluster segregation in Ag-TiCN bioactive coatings by RBS, GDOES, and ARXPS
}

\author{
R. Escobar Galindo • N. K. Manninen • C. Palacio • \\ S. Carvalho
}

Received: 4 March 2013 / Revised: 7 May 2013 / Accepted: 8 May 2013 /Published online: 31 May 2013

(C) Springer-Verlag Berlin Heidelberg 2013

\begin{abstract}
Surface modification by means of wear protective and antibacterial coatings represents, nowadays, a crucial challenge in the biomaterials field in order to enhance the lifetime of bio-devices. It is possible to tailor the properties of the material by using an appropriate combination of high wear resistance (e.g., nitride or carbide coatings) and biocide agents (e.g., noble metals as silver) to fulfill its final application. This behavior is controlled at last by the outmost surface of the coating. Therefore, the analytical characterization of these new materials requires high-resolution analytical techniques able to provide information about surface and depth composition down to the nanometric level. Among these techniques are Rutherford backscattering spectrometry (RBS), glow discharge optical emission spectroscopy (GDOES), and angle resolved X-ray photoelectron spectroscopy (ARXPS). In this work, we present a comparative RBS-GDOES-ARXPS study of the surface characterization of $\mathrm{Ag}-\mathrm{TiCN}$ coatings with $\mathrm{Ag} / \mathrm{Ti}$ atomic ratios varying from 0 to 1.49 , deposited at room temperature and $200{ }^{\circ} \mathrm{C}$. RBS analysis allowed a precise quantification of the
\end{abstract}

\author{
R. Escobar Galindo $(\square)$ \\ Instituto de Ciencia de Materiales de Madrid (ICMM-CSIC), \\ Cantoblanco, 28049 Madrid, Spain \\ e-mail: rescobar@icmm.csic.es \\ N. K. Manninen $\cdot$ S. Carvalho \\ GRF-CFUM, Physics Department, University of Minho, \\ Campus of Azurém, 4800-058 Guimarães, Portugal \\ N. K. Manninen $\cdot$ S. Carvalho \\ SEG-CEMUC, Department of Mechanical Engineering, \\ University of Coimbra, Rua Luís Reis Santos, \\ 3030788 Coimbra, Portugal \\ C. Palacio \\ Departamento de Física Aplicada (CXII), Universidad Autónoma \\ de Madrid, Cantoblanco, 28049 Madrid, Spain
}

silver content along the coating with a non-uniform $\mathrm{Ag}$ depth distribution for the samples with higher Ag content. GDOES surface profiling revealed that the samples with higher Ag content as well as the samples deposited at $200{ }^{\circ} \mathrm{C}$ showed an ultrathin (1-10 nm) Ag-rich layer on the coating surface followed by a silver depletion zone $(20$ $30 \mathrm{~nm}$ ), being the thickness of both layers enhanced with Ag content and deposition temperature. ARXPS analysis confirmed these observations after applying general algorithm involving regularization in addition to singular value decomposition techniques to obtain the concentration depth profiles. Finally, ARXPS measurements were used to provide further information on the surface morphology of the samples obtaining an excellent agreement with SEM observations when a growth model of silver islands with a height $d=1.5 \mathrm{~nm}$ and coverage $\theta=0.20$ was applied to the sample with $\mathrm{Ag} / \mathrm{Ti}=1.49$ and deposited at room temperature.

Keywords Ag-TiCN · Surface characterization · SEM · RBS · GDOES · ARXPS

\section{Introduction}

The strategy of surface modification using coatings has proved to offer unique chemical and physical properties able to improve the biological response of biomaterials as well as the wear and corrosion resistance of the base material. The development of new functional coatings, namely DLC [1, 2], TiN [3, 4], TiCN [4], TiAlN [5], and TiSiCON [6, 7] among others, has enhanced the functional properties of different biomaterials. Moreover, the addition of $\mathrm{Ag}$ to wear protective coatings reduces the friction coefficient and the wear rate of transition metal nitrides and carbides [8,9]. The addition of Ag nanoclusters has been also pointed as an effective solution 
to reduce bacterial colonization on biomaterials surface, thus enhancing the lifetime of the bio-device [8, 10-15]. The antibacterial activity of silver is attributed to the release of ionized $\mathrm{Ag}^{+}$, which is claimed to cause the disruption of cell membrane and DNA damage [16]. The efficiency of Ag is mainly controlled by the morphology of silver particles (being known that the smaller particles are more effective in destroying the bacteria) $[17,18]$ and the interaction between the $\mathrm{Ag}$ particles and the electrolyte, which is mainly controlled by the amount of $\mathrm{Ag}$ clusters on the coating surface and the morphology of the matrix [11, 19]. Hence, the ultimate bioactive performance of the coatings will be driven by the outmost surface $(<10 \mathrm{~nm})$ in contact with the biological environment and high-resolution analytical techniques are needed to complete the characterization. Rutherford backscattering spectrometry (RBS), glow discharge optical emission spectroscopy (GDOES), and angle resolved X-ray photoelectron spectroscopy (ARXPS) are techniques able to provide information about surface and depth composition down to the nanometric level [20].

The co-deposition of transition metal nitrides $(\mathrm{MeN})$ and carbides $(\mathrm{MeC})$ provokes the formation of nanostructured coatings where Ag nanoclusters are dispersed through the base matrix, forming $\mathrm{Ag}$ clusters which size increases at higher silver contents $[9,11,21]$. Several authors have reported that silver clusters are able to diffuse in the base coating, which leads to a non-uniform $\mathrm{Ag}$ distribution along the coating thickness. Krzanowski et al. [22] produced SiC$\mathrm{Ag}$ and $\mathrm{HfC}-\mathrm{Ag}$ coatings by magnetron sputtering, and the authors found that, although the $\mathrm{Ag}$ particles were embedded in the matrix near the substrate, there was a silver depleted region followed by a surface-rich $\mathrm{Ag}$ layer. Adochite et al. [23] found that the co-deposition of Ag and $\mathrm{TiO}_{2}$ coatings resulted in a non-uniform chemical composition along the thickness, being determined that the silver content was higher near the substrate and lower at the coating surface which was ascribed to diffusion of this element during the deposition process itself. The segregation of Ag to coating surface after annealing was also reported by several authors, who proposed the use of selflubricant films based on hard coatings combined with a ductile and lubricant $\mathrm{Ag}$ phase $[9,24,25]$. In fact, the surface segregation of $\mathrm{Ag}$ in different coatings is claimed to be a dynamic process that occurs even at room temperature [26]. Bates Jr. et al. [26] found that the co-deposition of $\mathrm{Ag}-\mathrm{Si}$ led to the surface segregation of $\mathrm{Ag}$, which was attributed to the immiscibility of $\mathrm{Ag}$ and $\mathrm{Si}$. The authors stated that the large surface and strain energies of Ag precipitates in the silicon matrix could further exclude the silver particles from the Si. Manninen et al. [21] performed previous studies in the Ag-TiCN system concluding that the coatings are composed by $\mathrm{TiCN}, \mathrm{a}-\mathrm{C}$ and $\mathrm{a}-\mathrm{CN}_{\mathrm{x}}$ phases, and crystalline $\mathrm{Ag}$ phases, being the size of the $\mathrm{Ag}$ grains and the presence of amorphous phases enhanced at higher silver contents. The tribological tests of these coatings were performed in bovine serum solution against an alumina counterpart in order to simulate the environment found in hip joints [8]. The results obtained indicated that the wear resistance of the coatings was enhanced for $\mathrm{Ag} / \mathrm{Ti}$ ratios lower than 0.20 (Ag content below 6 at.\%), while for higher silver contents the wear rate increased. Moreover, the cytotoxicity tests revealed that the mortality rate in MTS assay with fibroblasts was inferior to $10 \%$ for $\mathrm{Ag} / \mathrm{Ti}<1$, while for the coating with higher $\mathrm{Ag}$ content (27 at.\%) the mortality rate increased to $20 \%$, still being an acceptable result. The results found in previous studies were encouraging indicating that $\mathrm{Ag}-\mathrm{TiCN}$ coatings are a suitable option as wear protective coatings for hip implants.

Despite of these numerous and excellent works, the mechanism of silver surface segregation and its effect on the bioactivity of the coatings is still not fully understood. The purpose of this paper is, by the use of advanced surface characterization techniques, to shed light on the role of silver nanoclusters at the nanometer scale. In particular, this report aims to obtain a detailed characterization of the Ag composition profile along the depth as well as metal nanocluster size distribution at the surface as function of silver content (from 0 to 27 at.\%) and deposition temperature (room temperature and $200{ }^{\circ} \mathrm{C}$ ) for coatings prepared by reactive magnetron sputtering. As previously mentioned, the size distribution and amount of $\mathrm{Ag}$ clusters on the coating surface exert a strong influence on the tribological and biological behavior of these coatings. In this sense, the optimization of this system requires a deep knowledge of the surface properties of $\mathrm{Ag}$ $\mathrm{TiCN}$ (i.e., Ag particle size and surface coverage) in order to obtain an effective bioactive coating.

\section{Experimental details}

$\mathrm{Ag}-\mathrm{TiCN}$ coatings were deposited by reactive DC magnetron sputtering both onto polished and ultrasonically cleaned $316 \mathrm{~L}$ stainless steel $\left(20 \times 20 \mathrm{~mm}^{2}\right)$ and single crystalline silicon (100) substrates. A pure titanium interlayer was deposited in order to improve the adhesion. A high-purity Ti target (200× $\left.100 \mathrm{~mm}^{2}\right)$ and a mixed Ti/Ag target $\left(200 \times 100 \mathrm{~mm}^{2}\right)$ were used in a $\mathrm{Ar}+\mathrm{C}_{2} \mathrm{H}_{2}+\mathrm{N}_{2}$ atmosphere, with the substrates rotating at $70 \mathrm{~mm}$ over the target at a constant speed of $7 \mathrm{rpm}$. Two series of samples were deposited using a Ti target with 6 and $14 \mathrm{Ag}$ nuggets, resulting in relative $\mathrm{Ag}$ sputtering areas (only the preferential eroded zone of the target is considered) of $15 \%$ (first series) and $43 \%$ (second series), respectively. Argon flow was kept constant at $60 \mathrm{sccm}$ while the reactive gases fluxes $\left(\mathrm{C}_{2} \mathrm{H}_{2}\right.$ and $\left.\mathrm{N}_{2}\right)$ were changed. Further details concerning the deposition parameters can be seen elsewhere [21]. The variation in the reactive gas fluxes was performed in 
order to maintain approximately constant the $\mathrm{C}$ and the $\mathrm{N}$ contents, although the current density applied to the targets was changed in order to obtain coatings with different $\mathrm{Ag} / \mathrm{Ti}$ ratios, ranging from 0 to 1.49 . The deposition was carried at a constant voltage of $-70 \mathrm{~V}$. The base pressure in the deposition chamber was about $10^{-3} \mathrm{~Pa}$ and rose up to values between $3.1 \times 10^{-1}$ and $4.7 \times 10^{-1} \mathrm{~Pa}$ during the deposition. Two series of samples were deposited at different temperatures: room temperature (RT) and $200{ }^{\circ} \mathrm{C}$.

Ball crater test was used to determine the coatings thickness. The coatings chemical composition was determined by electron probe microanalysis (EPMA) in a Cameca SX 50 apparatus. The coating's morphology was evaluated by scanning electron microscopy (EDAX - Nova nanoSEM200) operating at $15 \mathrm{kV}$ in backscattered electron (BSE) mode.

In order to analyze the chemical composition depth profiles of the coatings, Rutherford backscattering spectroscopy (RBS) and glow discharge optical emission spectroscopy (GDOES) were carried out. RBS experiments were performed at the 5MV HVEE Tandetron accelerator sited at the Centro de Micro-Análisis de Materiales of Universidad Autónoma de Madrid [27]. The RBS experiments were performed using 3.7 $\mathrm{MeV} \mathrm{He}{ }^{+}$ions to make use of the resonance ${ }^{14} \mathrm{~N}(\alpha$, $\alpha)^{14} \mathrm{~N}$ in order to improve the sensitivity to nitrogen. The data were acquired simultaneously with two silicon surface barrier detectors located at scattering angles of $170^{\circ}$ and $135^{\circ}$, respectively, with an energy resolution of $16 \mathrm{keV}$ at an ion dose of $10 \mu \mathrm{C}$. The experimental spectra were fitted with the software programs RBX [28] and SIMRA [29]. GDOES depth profile analysis of the coatings was completed using a Horiba Jobin Yvon RF GD Profiler equipped with a 4-mmdiameter copper anode and operating in argon gas [30, 31]. In previous works $[32,33]$, Escobar Galindo et al. performed a complete optimization of the operating conditions for the analysis using this GDOES system. By applying a radiofrequency discharge pressure of $650 \mathrm{~Pa}$ and a forward power of $40 \mathrm{~W}$, multilayers in the nanometer range were able to be analyzed. Therefore, in this study these operation settings have been kept fixed. The setup was calibrated using standard materials of known composition. In order to improve the quantification of nitrogen, a series of nitride coatings deposited by magnetron sputtering was used as calibration samples [34]. The emission responses from the excited sputtered elements were detected with a polychromator of focal length of $500 \mathrm{~mm}$. The optical path of the spectrometer is nitrogen purged. The emission lines used were $130.217 \mathrm{~nm}$ for oxygen, $149.262 \mathrm{~nm}$ for nitrogen, $156.14 \mathrm{~nm}$ for carbon, $365.35 \mathrm{~nm}$ for titanium, $328.08 \mathrm{~nm}$ for silver, $271.441 \mathrm{~nm}$ for iron, 341.477 for nickel, and $425.433 \mathrm{~nm}$ for chromium. The chamber was cleaned by sputtering a silicon (100) sample for $20 \mathrm{~min}$ prior to the measurements. This procedure minimizes the contamination of the samples from the source, allowing a faster stabilization of the plasma and, therefore, a higher surface resolution of the GDOES setup [20]. No memory effects were observed after this pre-sputtering procedure. The uncertainties of GDOES measurements were estimated of $10 \%$ in the thickness and of lower than \pm 5 at. $\%$ in the silver concentration.

The electron spectroscopy measurements were performed in an ultra-high vacuum (UHV) system at a base pressure better than $8 \times 10^{-8} \mathrm{~Pa}$. The XPS spectra were measured using a hemispherical analyzer (SPECS Phoibos 100 MCD-5). The pass energy was $9 \mathrm{eV}$, giving a constant resolution of $0.9 \mathrm{eV}$. The $\mathrm{Au} 4 \mathrm{f}_{7 / 2}, \mathrm{Ag} 3 \mathrm{~d}_{5 / 2}$, and $\mathrm{Cu} 2 \mathrm{p}_{3 / 2}$ lines of reference samples at 84.0, 368.3, and $932.7 \mathrm{eV}$, respectively, were used to calibrate binding energies. A twin anode ( $\mathrm{Mg}$ and $\mathrm{Al}$ ) X-ray source was operated at a constant power of $300 \mathrm{~W}$ using $\mathrm{Mg}$ $\mathrm{K}_{\alpha}(1,253.4 \mathrm{eV})$ radiation. The analyzed area, which is controlled by the entrance slit of the analyzer, is a circle of around $3.5 \mathrm{~mm}$ in diameter. In addition to that, the samples were placed in a sample stage with four degrees of freedom in such a way that the angle between the axis of the input lens of the analyzer and the surface normal could be varied between $0^{\circ}$ and $70^{\circ}$ in order to perform angle-resolved measurements.

\section{Results and discussion}

Chemical composition and morphology of Ag-TiCN coatings

As mentioned above, we have previously reported [21] a complete description of the deposition parameters, chemical bulk composition, and structural characterization of $\mathrm{Ag}$ TiCN coatings deposited at room temperature. The deposition rate and the variations in the chemical composition were found to be mainly controlled by the increase in the current density applied to the targets and the reactive gas flow. According to the chemical composition obtained by EPMA, it was found that the Ag content increased from 0 to 27 at.\% along with a decrease in the Ti content from 37 at.\% to 18 at.\%. The $\mathrm{C}$ and $\mathrm{N}$ contents were almost constant for the studied samples. Taking into account that the variations in Ag content were accomplished by reducing the Ti content, the coatings were labeled according to their $\mathrm{Ag} / \mathrm{Ti}$ atomic ratios. For this paper, we have selected four samples with different $\mathrm{Ag} / \mathrm{Ti}$ ratios $(0,0.2,0.4$, and 1.49) and prepared at room temperature and at $200{ }^{\circ} \mathrm{C}$. In Table 1 , a summary of the $\mathrm{Ag} / \mathrm{Ti}$ ratios, Ag contents, and deposition rates is shown. The coatings deposition rate varies from 1.1 to $1.8 \mu \mathrm{m} / \mathrm{h}$ with the silver content, being clear that the deposition rates are similar for both temperatures.

Figure 1 shows the plain view BSE micrographs of the coatings with different $\mathrm{Ag} / \mathrm{Ti}$ atomic ratios deposited at $\mathrm{RT}$ (left) and $200{ }^{\circ} \mathrm{C}$ (right). The distributions of diameters, median of the cluster diameter distribution, and standard deviation of the log-normal fit are also presented for samples $\mathrm{Ag} / \mathrm{Ti}=0.40$ 
Table 1 Silver content, thickness of deposited samples, and results from SEM images analysis

\begin{tabular}{|c|c|c|c|c|c|c|c|}
\hline \multirow[t]{2}{*}{$\mathrm{Ag} / \mathrm{Ti}$ ratio } & \multirow[t]{2}{*}{ Ag content (at. $\%)$} & \multicolumn{2}{|c|}{ Thickness $(\mu \mathrm{m})$} & \multicolumn{2}{|c|}{ Ag surface area (\%) } & \multicolumn{2}{|c|}{$\mathrm{Ag}$ average diameter $(\mathrm{nm})$} \\
\hline & & RT & $200{ }^{\circ} \mathrm{C}$ & RT & $200{ }^{\circ} \mathrm{C}$ & RT & $200{ }^{\circ} \mathrm{C}$ \\
\hline 0 & 0 & 2.9 & 2.5 & 0.00 & 0.00 & - & - \\
\hline 0.20 & 6 & 1.4 & 1.4 & 0.00 & 0.00 & - & - \\
\hline 0.40 & 11 & 3.0 & 3.0 & $0.10 \pm 0.05$ & $0.50 \pm 0.20$ & $24 \pm 6$ & $26 \pm 6$ \\
\hline 1.49 & 27 & 3.2 & 3.1 & $13 \pm 1$ & $15 \pm 2$ & $30 \pm 7$ & $54 \pm 25$ \\
\hline
\end{tabular}

and 1.49 either deposited at RT and $200{ }^{\circ} \mathrm{C}$, and the data are summarized in Table 1. The BSE imaging mode allows obtaining the elemental contrast of Ag, which appears brighter in the dark TiCN matrix due to its higher atomic mass. From the BSE micrographs of the samples $\mathrm{Ag} / \mathrm{Ti}=0.40$ and 1.49 , it can be found that $\mathrm{Ag}$ nanoclusters are embedded in the TiCN matrix. Since silver is immiscible in TiCN matrix, the deposition of $\mathrm{Ag}-\mathrm{TiCN}$ coatings results in the formation of nanocomposites with silver nanoparticles embedded in the
TiCN matrix. The presence of metallic silver as well as the formation of crystalline TiCN phases was previously confirmed by means of XRD and XPS analysis, and the results can be found elsewhere [21]. However, since the backscattered electrons are produced at high depths (about $1 \mu \mathrm{m}$ ) we cannot infer that the Ag clusters are formed at the outmost surface of the coatings.

Regarding the sample with $\mathrm{Ag} / \mathrm{Ti}=0.20$, the presence of Ag clusters was not detected in SEM analysis for the coatings
Fig. 1 SEM micrographs: a Ag/ $\mathrm{Ti}=0.2, \mathrm{RT} ; \mathbf{b} \mathrm{Ag} / \mathrm{Ti}=0.2$, $200{ }^{\circ} \mathrm{C} ; \mathbf{c ~ A g} / \mathrm{Ti}=0.4, \mathrm{RT} ; \mathbf{d ~ A g} /$ $\mathrm{Ti}=0.4,200^{\circ} \mathrm{C} ; \mathbf{e ~} \mathrm{Ag} / \mathrm{Ti}=1.49$, $\mathrm{RT}$; and $\mathbf{f} \mathrm{Ag} / \mathrm{Ti}=1.49,200{ }^{\circ} \mathrm{C}$
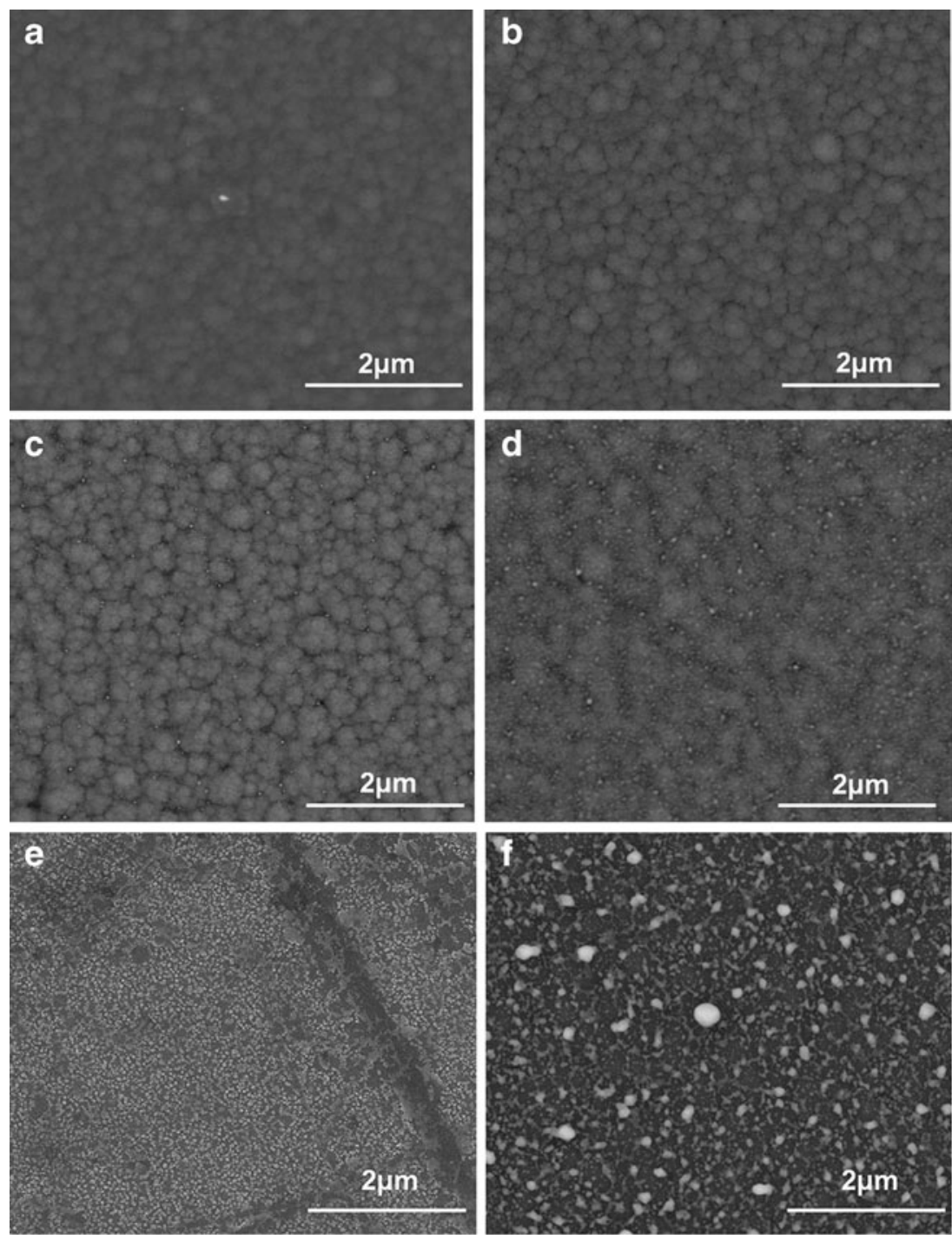
deposited at RT and $200{ }^{\circ} \mathrm{C}$ (Fig. 1a, b), which is plausible due to their small size. The increase of $\mathrm{Ag} / \mathrm{Ti}$ to 0.40 resulted in the segregation of small Ag clusters to the column boundaries as shown in Fig. 1c for the sample deposited at RT. The average size of the Ag clusters is $24 \pm 6 \mathrm{~nm}$ (see histogram in Fig. 2a). Increasing the $\mathrm{Ag}$ content on the coatings $(\mathrm{Ag} / \mathrm{Ti}=1.49)$ results in the formation of larger clusters (with an average size of $30 \pm 7 \mathrm{~nm}$ as presented in Fig. 2c) due to the coalescence during the growth process (Fig. 1e). The increase of $\mathrm{Ag}$ clusters size with $\mathrm{Ag}$ content was previously reported by several authors $[21,35]$. Deposition of the films at higher temperature $\left(200{ }^{\circ} \mathrm{C}\right)$ led to the increase of $\mathrm{Ag}$ cluster size up to $26 \pm 6$ and $54 \pm 25 \mathrm{~nm}$ for the samples with $\mathrm{Ag} / \mathrm{Ti}=0.40$ and 1.49, respectively, as observed in Fig. 1d (see histogram in Fig. 2b) and 1f (see histogram in Fig. 2d). This effect is attributed to the higher Ag mobility promoted by the temperature increase, being the effect more pronounced for the samples with the highest $\mathrm{Ag}$ content $(\mathrm{Ag} / \mathrm{Ti}=1.49)$. Liu et al. [36] reported that the co-deposition of $\mathrm{Ag}-\mathrm{Si}$ at $20^{\circ} \mathrm{C}$ and $200{ }^{\circ} \mathrm{C}$ led to the formation of $\mathrm{Ag}$ nanoclusters embedded in the $\mathrm{Si}$ matrix, and the nanocomposite films deposited at $200{ }^{\circ} \mathrm{C}$ tend to grow large and well-separated $\mathrm{Ag}$ particles while the films deposited at room temperature grow finer $\mathrm{Ag}$ particles and their clusters.

In the first section, we have summarized the chemical composition and the morphology of AgTiCN coatings

a

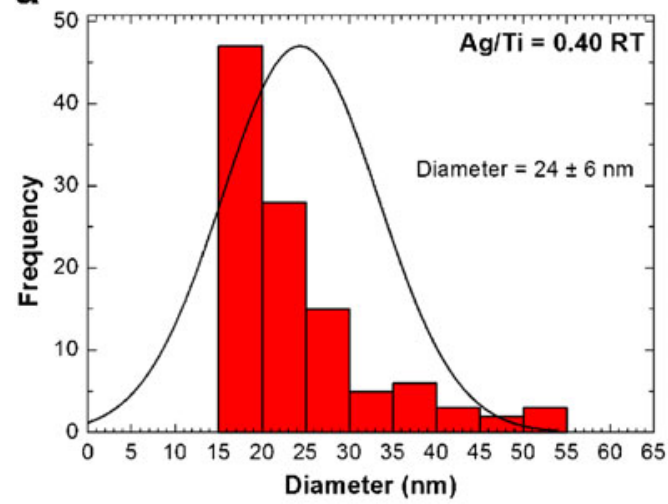

C

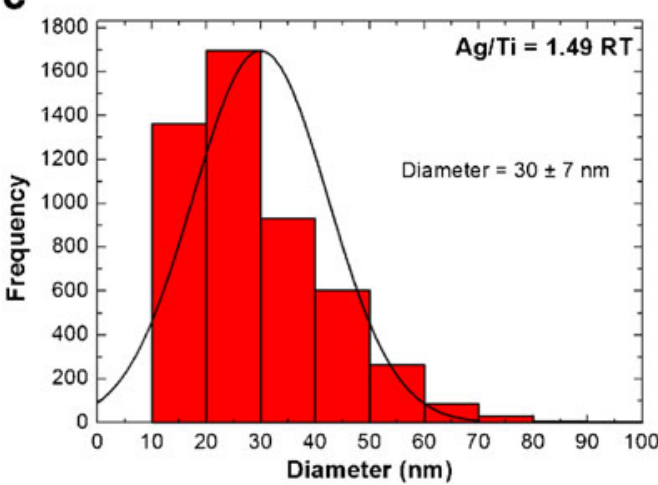

deposited with different $\mathrm{Ag} / \mathrm{Ti}$ ratios and at two different temperatures (room temperature and $200{ }^{\circ} \mathrm{C}$ ). Due to the depth resolution of EPMA (about $2 \mu \mathrm{m}$ ), the chemical composition thereby obtained is related only to the bulk of the coating. In the same direction, the BSE imaging mode of SEM, although allowing to unambiguously detect the formation of silver clusters, cannot be used to conclude that they are formed at the surface of the coatings. Therefore, in the following sections we will make use of surface techniques (RBS, GDOES, and ARXPS) to obtain, on the one hand, the compositional depth profiles of the coatings ("Compositional RBS and GDOES depth profiles of AgTiCN coatings") and, on the other, precise information of the segregation of silver on the surface of the coatings as a function of the silver content and deposition temperature (“Ag surface depth profile and segregation").

Compositional RBS and GDOES depth profiles of AgTiCN coatings

Firstly, we have made use of RBS and GDOES as tools to obtain the compositional depth profiles of all the AgTiCN samples deposited at the different $\mathrm{Ag} / \mathrm{Ti}$ ratios and deposition temperatures. As an example, the RBS spectra and the GDOES composition depth profile of the sample with $\mathrm{Ag} / \mathrm{Ti}=1.49$ (deposited at $200{ }^{\circ} \mathrm{C}$ ) are presented in Fig. 3a and b, respectively.

b

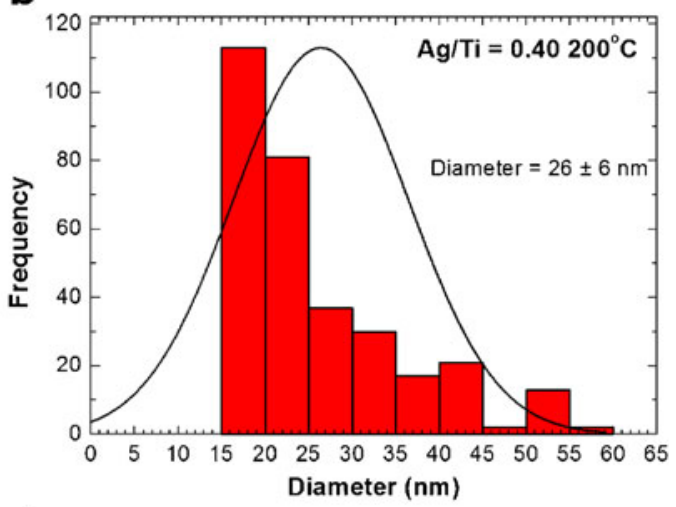

d

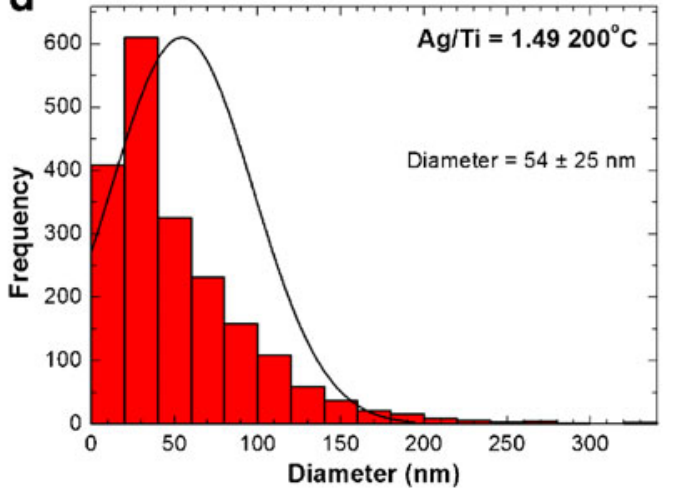

Fig. 2 Histograms of silver cluster diameter for a $\mathrm{Ag} / \mathrm{Ti}=0.4, \mathrm{RT} ; \mathbf{b ~ A g} / \mathrm{Ti}=0.4,200{ }^{\circ} \mathrm{C} ; \mathbf{c ~} \mathrm{Ag} / \mathrm{Ti}=1.49, \mathrm{RT}$; and $\mathbf{d ~} \mathrm{Ag} / \mathrm{Ti}=1.49,200{ }^{\circ} \mathrm{C}$ samples 
For clarity purposes, the RBS experimental data and the global fitting of results were shifted vertically from the contributions of the elemental spectra (lower part of the graphs) in Fig. 3a. RBS fitting of the experimental results gave very good agreement once we used a multilayer stack to describe the sample. At the surface, there is a very thin layer of about $170 \times 10^{15}$ at $\mathrm{cm}^{-2}$ with a high content of $\mathrm{Ag}$ (up to 30 at.\%). Below this surface layer, there is a thin AgTiCN layer of about $910 \times 10^{15}$ at $\mathrm{cm}^{-2}$ with a lower composition of $\mathrm{Ag}(15-$ 18 at.\%) than the bulk AgTiCN coating (20-25 at.\%) that was fitted to have $15 \times 10^{18}$ at $\mathrm{cm}^{-2}$. All those layers showed a very well-defined multilayer coating structure with sharp interfaces down to the limit of the technique (i.e., 5-10 nm). Similar multilayer fitting was applied to the rest of the deposited coatings and they will be discussed in detailed to elucidate the silver surface segregation in the coatings (see " $\mathrm{Ag}$ surface depth profile and segregation").

With respect to the GDOES depth profile (Fig. 3b), it can be observed how the elemental composition is very homogeneous within the bulk deposited coating (i.e., thickness above $100 \mathrm{~nm}$ ) until reaching the Ti interlayer. However, in the inset of Fig. 3b, it can be found that in the first $50 \mathrm{~nm}$ the $\mathrm{Ti}, \mathrm{N}$, and $\mathrm{C}$ contents increase, along with a decrease in the Ag content. In fact, the $\mathrm{Ag}$ content decreases from 31 at. $\%$ to 15 at. $\%$ in the first $20 \mathrm{~nm}$ and aftermost it increases to 21 at.\% showing a constant value after the first $100 \mathrm{~nm}$ until the titanium interlayer is reached at about $3 \mu \mathrm{m}$, in excellent agreement with RBS measurements.

Therefore, both RBS and GDOES analysis are consistent with the quantitative chemical composition obtained by EPMA for the bulk coating. However, they provide richer information regarding the compositional depth profile of the films. In particular, it was found that on the surface of the coatings there is a non-homogenous chemical composition. In "Ag surface depth profile and segregation", we will focus on the silver depth profile at the surface of the coatings in order to study the evolution of the silver surface segregation for the different silver contents and temperatures.

Ag surface depth profile and segregation

In Fig. 4a and b, we show a zoom of the RBS spectra of the different coatings deposited at $\mathrm{RT}$ and $200{ }^{\circ} \mathrm{C}$, respectively. The range of selected RBS energies allows comparing the segregation of silver in the different deposited samples. The surface $\mathrm{Ag}$ is detected in RBS at a typical energy of $3,190 \mathrm{keV}$ and with decreasing energy along the sample depth due to the energy loss of $\mathrm{He}^{+}$ions. In addition, the surface titanium signal appears at energy of $2,660 \mathrm{keV}$ for all the studied samples.

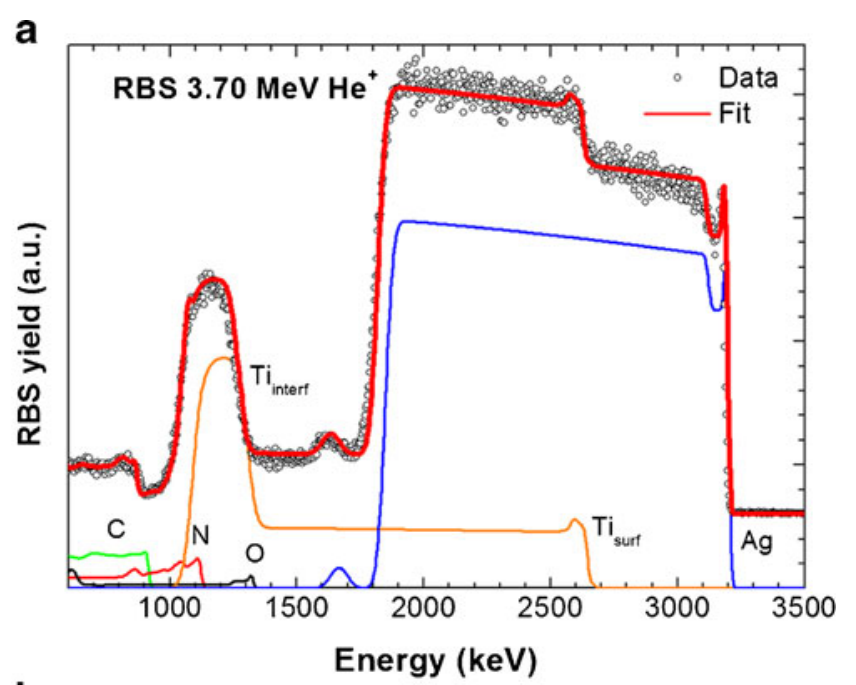

b

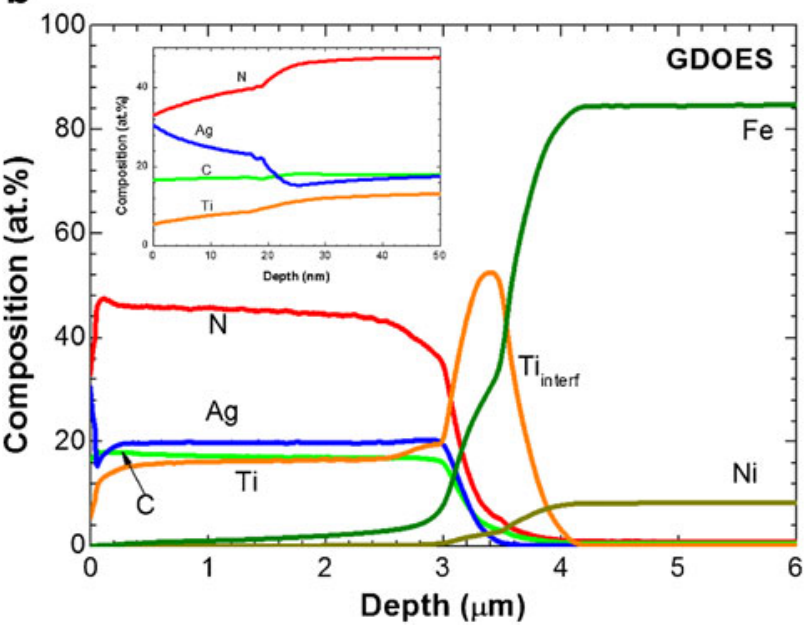

Fig. 3 RBS spectra (a) and GDOES depth profile (b) of sample $\mathrm{Ag} / \mathrm{Ti}=1.49$ deposited at $200{ }^{\circ} \mathrm{C}$. The inset in (b) shows a zoom of the first $50 \mathrm{~nm}$ of the GDOES profile

According to the results, it can be found that for samples with $\mathrm{Ag} / \mathrm{Ti}=1.49$ there is a very thin top surface layer with a high silver content (zone 1) in the schematic representation of Fig. $4 \mathrm{~b}$ followed by a silver depletion zone (zone 2) before reaching the silver content of the bulk coating (zone 3 ). For the sample deposited at room temperature, RBX and SIMRA simulations asses the areal density of the top Ag layer and the depletion zone to be of 40 and $400 \times 10^{15}$ at cm$^{-2}$, respectively. In the case of the $\mathrm{Ag} / \mathrm{Ti}=1.49$ sample deposited at $200{ }^{\circ} \mathrm{C}$, those areal densities were estimated to be of 170 and $910 \times 10^{15}$ at $^{-2}$ for the top silver layer and the silver depletion zone, respectively. Therefore, it can be observed that an increase of the deposition temperature provoked a surface modification of the AgTiCN that extends two to three times in depth as compared to the sample deposited at room temperature (assuming that there is no substantial change in the density of the films upon deposition at temperature). With respect to the samples prepared with lower $\mathrm{Ag} / \mathrm{Ti}$ ratio $(0.20$ 
and 0.40), the RBS spectra of both samples deposited at RT and $200{ }^{\circ} \mathrm{C}$ did not reveal any silver surface segregation.

In order to evaluate more accurately this silver surface segregation effect in the coatings, we have made use of the higher depth resolution at the surface provided by GDOES depth profile analysis. In fact, GDOES has a monolayer resolution at the surface and no worse than $1 \mathrm{~nm}$ for the first $100 \mathrm{~nm}$, while RBS shows a depth resolution of 5$10 \mathrm{~nm}$ [20]. GDOES depth profiles of the samples are presented in Fig. 5a and b for all the coatings deposited at $\mathrm{RT}$ and $200{ }^{\circ} \mathrm{C}$, respectively.

From Fig. 5a, it can be found that the Ag content of the coating with $\mathrm{Ag} / \mathrm{Ti}=1.49$ decreases from 46 at.\% to 12 at.\% along the first $5 \mathrm{~nm}$, after which it increases again reaching a constant value of 21 at.\% along the coating thickness. This is consistent with the RBS results that predicted a top layer with high silver content and a subsequent silver depletion zone. On the contrary, no silver segregation was observed for samples $\mathrm{Ag} / \mathrm{Ti}=0.40$ and 0.20 . It is worth noting that the GDOES results obtained for the coating with $\mathrm{Ag} / \mathrm{Ti}=0.40$ show an increase from 0 at. $\%$ to 12 at. $\%$ in the first $13 \mathrm{~nm}$ of the film. The absence of Ag in the surface of this particular coating (corroborated by ARXPS as explained below) confirms that the silver precipitates present in the SEM image of Fig. 1c can be observed because we are using the BSE imaging mode and not because there is any surface segregation. Regarding the samples deposited at $200{ }^{\circ} \mathrm{C}$ all the GDOES profiles show a clear silver surface segregation promoted by diffusion process, followed by a silver depletion zone. Moreover, it is found that after this decrease the Ag content increases again to a constant silver bulk concentration. We have located the different interfaces $(1-$ silver top layer, 2-silver depletion layer, and 3-depth where the silver bulk composition is attained) according to the generally used (50/50 \%) definition given by Hofmann [37]. As an example, in Fig. 5a we indicated the different layers for the sample deposited at room temperature with $\mathrm{Ag} / \mathrm{Ti}=1.49$. In Table 2, the thicknesses of the layers for the different deposited samples are summarized.

The thickness of the silver top layer increases from $3 \mathrm{~nm}$ for the sample with $\mathrm{Ag} / \mathrm{Ti}=0.20$ up to 18 and $22 \mathrm{~nm}$ for samples with ratios of 0.4 and 1.49 , respectively. The thickness of the depletion zone varies accordingly with the $\mathrm{Ag}$ content. For sample $\mathrm{Ag} / \mathrm{Ti}=0.20$, the depletion zone is as thin as $3 \mathrm{~nm}$ reaching a constant $\mathrm{Ag}$ bulk content of 45 at.\% before the first $10 \mathrm{~nm}$ of depth. The depletion zone extends to higher depths with the Ag content as can be observed in the inset of Fig. 5b showing the silver depth profile along the first $\approx 20 \mathrm{~nm}$ of samples $\mathrm{Ag} / \mathrm{Ti}=0.40$ and 1.49. For sample with ratio 0.4 , the thickness of the depletion zone was measured to be of $10 \mathrm{~nm}$ reaching a constant bulk Ag content of $12-13$ at. $\%$ after the first $40 \mathrm{~nm}$ of depth. Of particular interest is sample with the highest $\mathrm{Ag}$ content
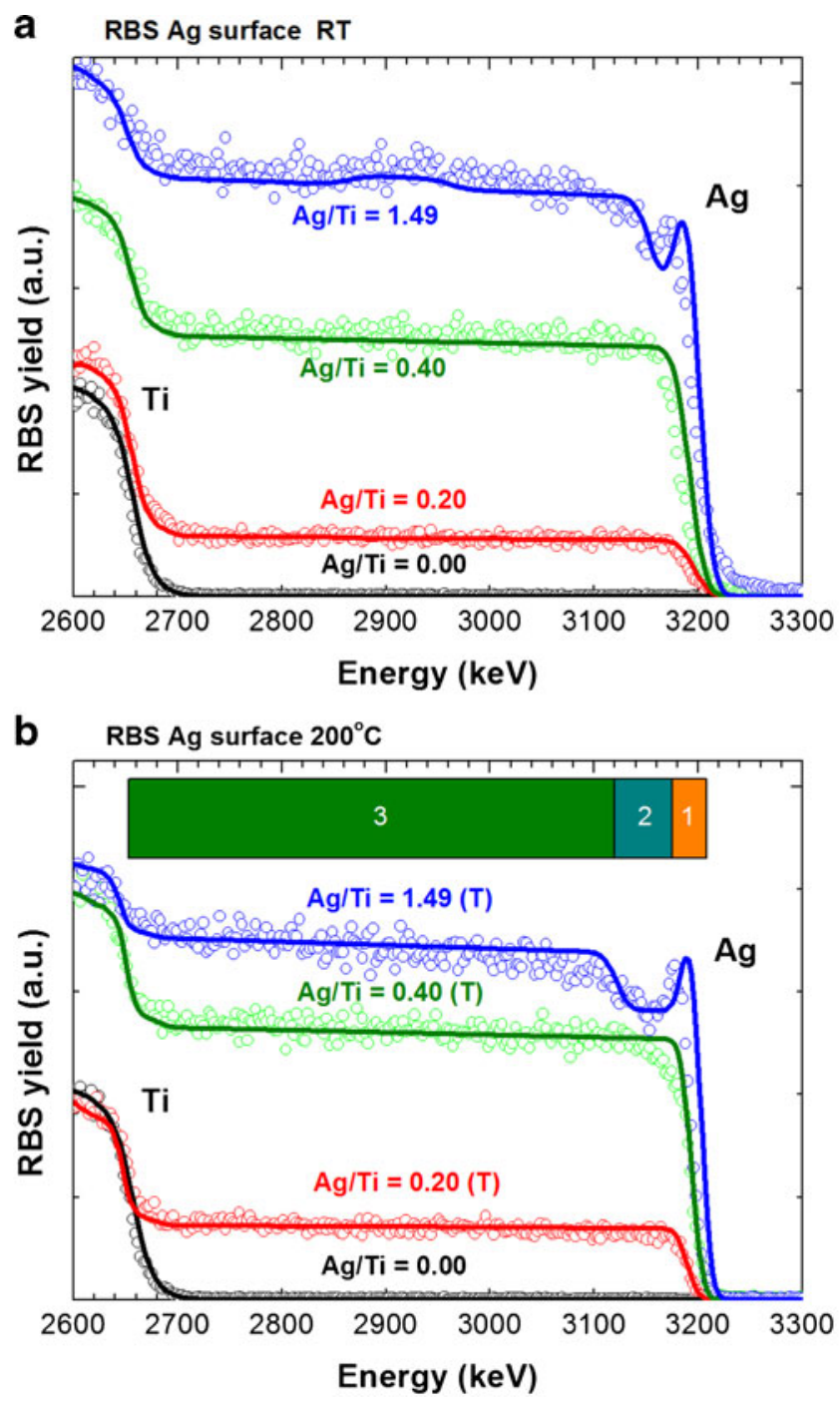

Fig. 4 RBS spectra of samples deposited $\mathbf{a}$ at RT and $\mathbf{b}$ at $200{ }^{\circ} \mathrm{C}$. Both graphs are in the same vertical scale. In (b), a schematic representation of the different silver regions ( 1 silver top layer, 2 silver depletion zone, 3 silver bulk value) is depicted

$(\mathrm{Ag} / \mathrm{Ti}=1.49)$ where a thickness of $30 \mathrm{~nm}$ was measured for the depletion zone, but the bulk Ag content of 20-22 at $\%$ was not reached until a depth of $150 \mathrm{~nm}$ typical of a diffusion-driven process (see Fig. 6).

The results obtained indicate that, regardless the deposition temperature, coatings with a silver content above a certain threshold ( $>20$ at. $\%$ in our case) show an Ag-rich layer on the coating surface below which a Ag depletion zone of few nanometers is formed. Similar results were obtained for all samples deposited at $200{ }^{\circ} \mathrm{C}$ even for very low silver contents, being the thickness of the formed layers dependent on the silver composition. Krzanowski et al. [22] also found an Agsurface-rich layer followed by a depletion zone; however, the thickness of the depletion zone was almost half of the coating thickness (about $500 \mathrm{~nm}$ ). The surface segregation of Ag was 

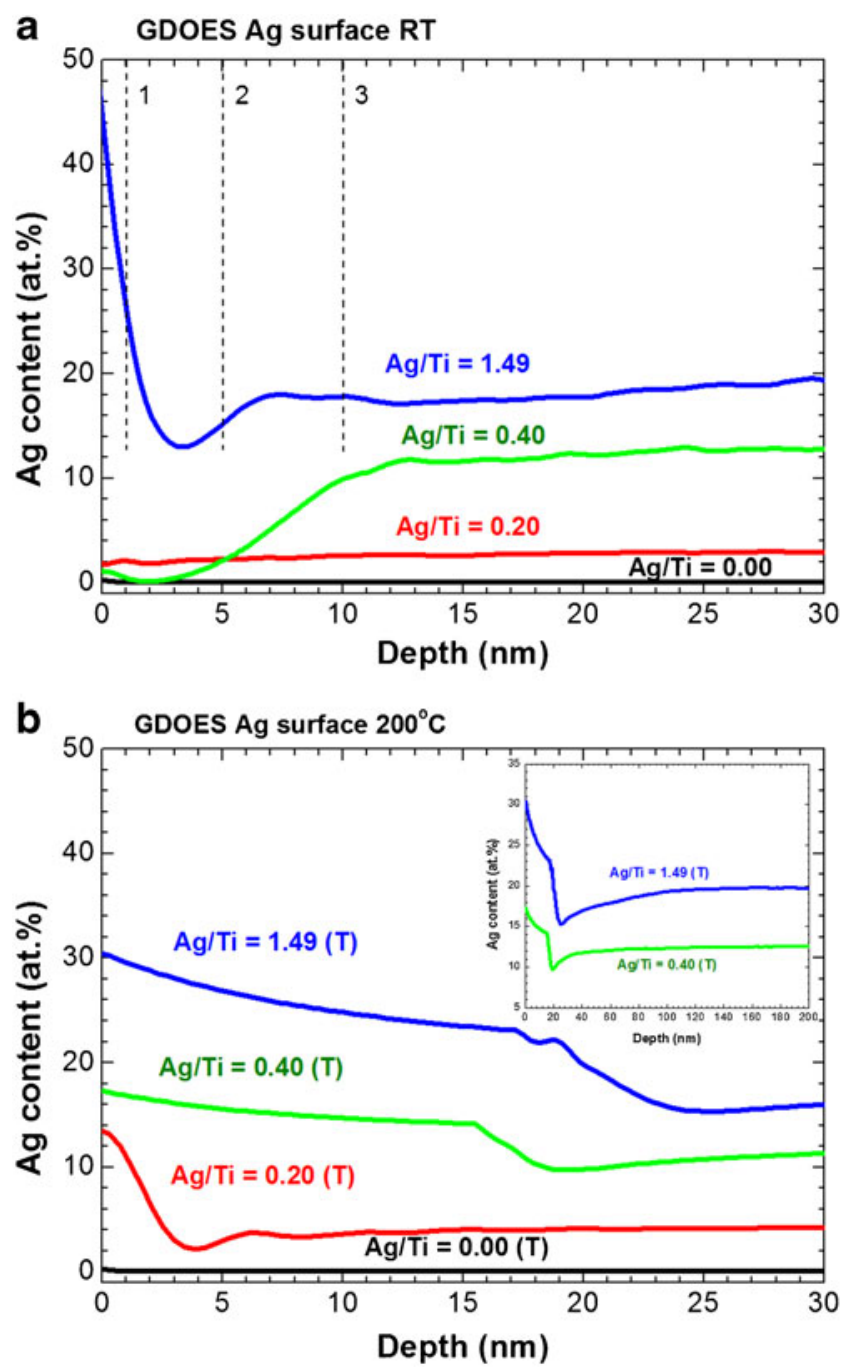

Fig. $5 \mathrm{Ag}$ depth profile near surface $(<30 \mathrm{~nm})$ for the coatings deposited at a RT and $\mathbf{b} 200^{\circ} \mathrm{C}$. The inset in (b) shows the extended depth profiles up to $200 \mathrm{~nm}$ for samples $\mathrm{Ag} / \mathrm{Ti}=0.40\left(200^{\circ} \mathrm{C}\right)$ and $\mathrm{Ag} / \mathrm{Ti}=1.49\left(200^{\circ} \mathrm{C}\right)$

previously reported by several authors [22, 24-26], and it is claimed that this process is driven by the decrease in the surface energy and strain energy associated with the Ag surface segregation [22, 24]. Both the increase in the deposition temperature [26] and annealing treatments [24] are able to activate the diffusion process. In fact, from the results obtained it seems clear that the segregation process depend on the $\mathrm{Ag}$ content and deposition temperature, being enhanced with these parameters.

In order to get further information on the near surface composition and morphology, ARXPS measurements were carried out. Figure 7a shows the measured $\mathrm{Ag}$ concentrations as a function of the emission angle for samples with different $\mathrm{Ag} / \mathrm{Ti}$ ratios $\left[\mathrm{Ag} / \mathrm{Ti}=1.49(\mathrm{RT}), \mathrm{Ag} / \mathrm{Ti}=0.2\left(200^{\circ} \mathrm{C}\right), \mathrm{Ag} / \mathrm{Ti}=\right.$ $0.4(\mathrm{RT})$, and $\mathrm{Ag} / \mathrm{Ti}=0]$, samples which are those where significant variations of the Ag near surface concentration were found using GDOES. It is worth noting that silver surface
Table 2 Thicknesses of the silver surface layer, depletion layer, and bulk depth measured from GDOES depth profiles for AgTiCN coatings

Sample Ag top surface (nm) Ag depletion (nm) Ag bulk depth (nm)

\begin{tabular}{|c|c|c|c|c|c|c|}
\hline & RT & $200^{\circ} \mathrm{C}$ & $\mathrm{RT}$ & $200^{\circ} \mathrm{C}$ & RT & $200^{\circ} \mathrm{C}$ \\
\hline 0.2 & - & 3 & - & 3 & - & 10 \\
\hline 0.4 & - & 18 & - & 10 & - & 40 \\
\hline 1.49 & 1 & 22 & 5 & 30 & 10 & 150 \\
\hline
\end{tabular}

The error in the thickness was estimated to be of $10 \%$

segregation was found for samples $\mathrm{Ag} / \mathrm{Ti}=1.49$ (RT) and $\mathrm{Ag} / \mathrm{Ti}=0.2\left(200{ }^{\circ} \mathrm{C}\right)$ but not for sample $\mathrm{Ag} / \mathrm{Ti}=0.4$ (RT) in complete concordance with GDOES results. Ag concentrations have been calculated from the signal intensities using the sensitivity factors provided by the manufacturer [38]. It is well known that if XPS spectra are recorded at different emission angles $\varphi$, the photoelectron escape depth, $\lambda \cos \theta$ (being $\lambda$ the attenuation length of emitted photoelectrons), can be varied in such a way that the depth analyzed is changed and therefore the set of angular measurements will contain information on the concentration depth profile of each species. In our case, the intensity of emitted photoelectrons corresponding to the Ag 3d XPS band is given by Eq. (1)

$I_{\mathrm{Ag}}(\varphi)=\frac{I_{\mathrm{Ag}}^{0}}{\lambda_{\mathrm{Ag}} \cos \phi} \int_{0}^{\infty} c_{\mathrm{Ag}}(z) \exp \left(\frac{-z}{\lambda_{\mathrm{Ag}} \cos \phi}\right) d z$

where $c_{\mathrm{Ag}}(z)$ is the $\mathrm{Ag}$ concentration at a depth $z$ assumed to be uniform on the surface; $\lambda_{\mathrm{Ag}}$ is the attenuation length of the photoelectron coming from $\mathrm{Ag} ; \varphi$ is the emission angle referred to the surface normal; and $I_{\mathrm{Ag}}{ }^{0}$ is a constant depending on instrumental factors, angular asymmetry, and photoionization cross-section [34] which is the intensity measured from a standard Ag sample using the same experimental conditions. Equation (1) is an integral equation of the first kind and represents a prototype of ill-posed problems [39]. If a general algorithm involving regularization in addition to singular value decomposition (SVD) techniques [34] without any prior hypothesis on the shape of the concentration depth profile is used to extract the concentration depth profiles, $c_{A g}(z)$, results of Fig. $7 \mathrm{~b}$ are obtained for samples $\mathrm{Ag} / \mathrm{Ti}=$ $1.49(\mathrm{RT})$ and $\mathrm{Ag} / \mathrm{Ti}=0.2\left(200^{\circ} \mathrm{C}\right)$, which are those where significant variations of the $\mathrm{Ag}$ near surface concentration were found using GDOES. As can be seen from the results of Fig. 7b, the agreement between ARXPS results and GDOES results of Fig. 5 for the same samples is very good clearly confirming a silver enrichment in the first $2-3 \mathrm{~nm}$ of the sample surface. It should be pointed out that the regularization parameter used for solving the integral Eq. (1) was 


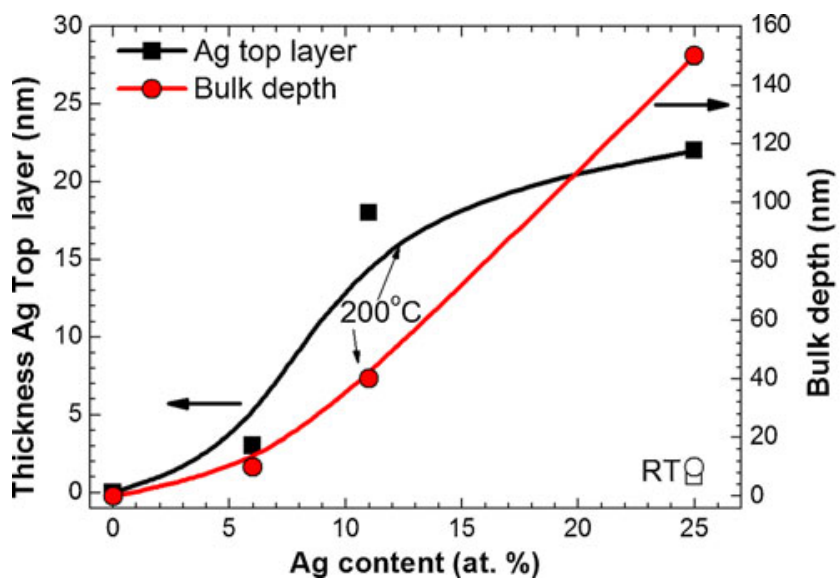

Fig. 6 Thickness of the Ag top layer (closed squares) and bulk depth (closed circles) as a function of the silver content in the samples prepared at $200{ }^{\circ} \mathrm{C}$. The open symbols represent the values for the sample $\mathrm{Ag} / \mathrm{Ti}=1.49$ deposited at room temperature. The continuous lines are plotted to guide the reader's eye

chosen in the limit of stability in order to avoid meaningful solutions.

ARXPS measurement can be also used to provide further information on the surface morphology. This task can be accomplished assuming some hypothesis on the depth profile shape. In general, such depth profile would be dependent of some parameters that could be used as fitting parameters to minimize in Eq. (1) the differences between the measured intensities and the calculated ones using the proposed test depth profile. Therefore, assuming that $\mathrm{Ag}$ forms islands of height $d$ and coverage $\theta$, that is, $C_{A g}(z)=1$ if $0 \leq z \leq d$ and $C_{A g}(z)=0$ otherwise (this hypothesis is supported by SEM micrographs of Fig. 1), we should have

$I_{\mathrm{Ag}}(\varphi)=I_{\mathrm{Ag}}^{0} \theta\left[1-\exp \left(-\frac{d}{\lambda \cos \varphi}\right)\right]$

where $\theta$ and $d$ have to be used as fitting parameters to minimize the differences between the right side of Eq. (2), representing the measured intensities (concentrations), and the left side, representing the calculated ones. Obviously the limit case $\theta=1$ represents the results related to a step-like profile instead of islands.

We have used the ARXPS results of Fig. 7a to test both possibilities (1) step-like profile and (2) islands for the $\mathrm{Ag}$ distribution. Figure 8 shows the ARXPS results for the $\mathrm{Ag} / \mathrm{Ti}=1.49$ and $\mathrm{Ag} / \mathrm{Ti}=0.2(\mathrm{~T})$ samples. Dashed lines in Fig. 8 represent the best fitting assuming $\theta=1$, that is, a steplike profile for the $\mathrm{Ag}$ concentration depth profile, whereas continuous lines represent the best-fitting assuming islands for the Ag distribution on the surface. The parameters leading to the best fit of the experimental data to an islands model are shown in Table 3.
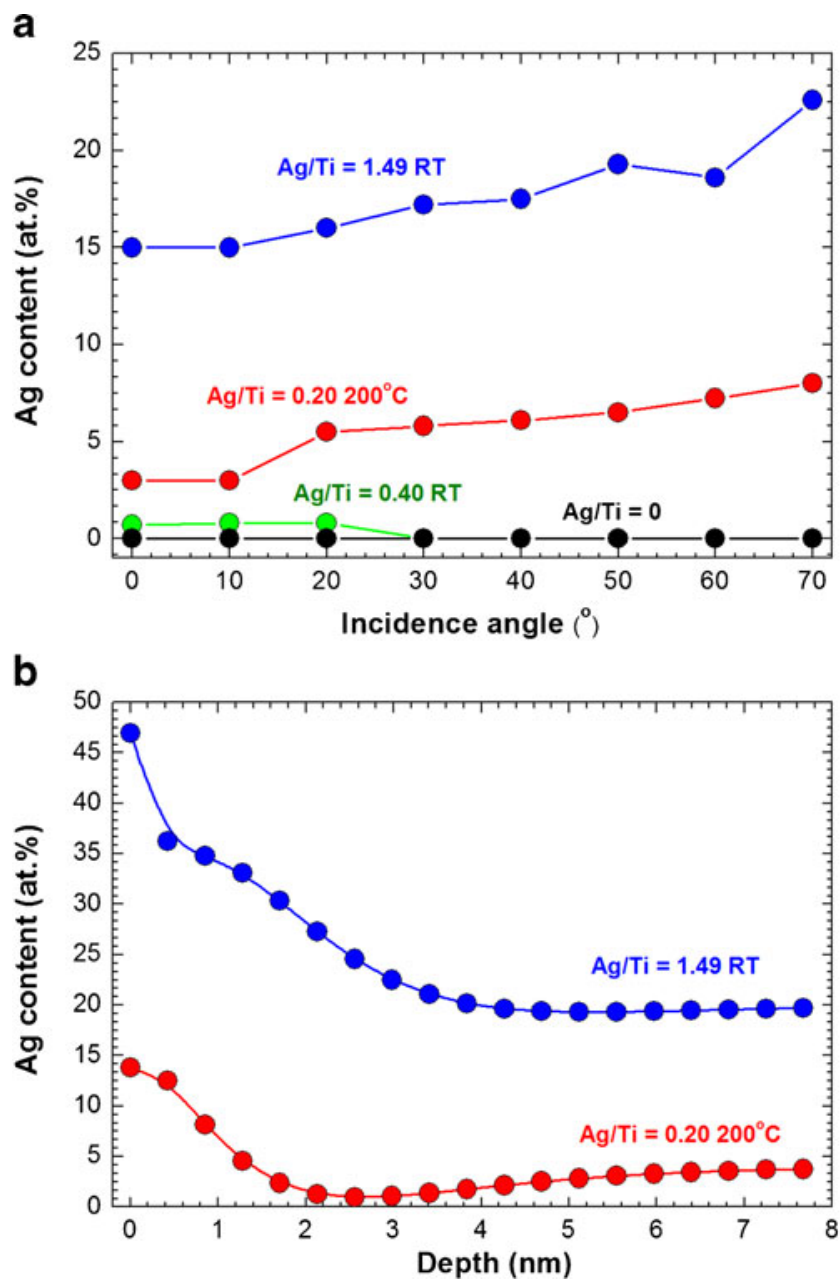

Fig. 7 a ARXPS data of samples $\mathrm{Ag} / \mathrm{Ti}=0, \mathrm{Ag} / \mathrm{Ti}=0.20\left(200{ }^{\circ} \mathrm{C}\right)$, $\mathrm{Ag} / \mathrm{Ti}=0.40(\mathrm{RT})$, and $\mathrm{Ag} / \mathrm{Ti}=1.49(\mathrm{RT})$. b Concentration depth profiles extracted from deconvolution of ARXPS data for samples Ag/ $\mathrm{Ti}=0.20\left(200{ }^{\circ} \mathrm{C}\right)$ and $\mathrm{Ag} / \mathrm{Ti}=1.49(\mathrm{RT})$

As observed in Fig. 8, clearly a model of Ag islands on the surface is more appropriate to explain the experimental data than a step-like profile. In particular, for the sample with low silver content $(\mathrm{Ag} / \mathrm{Ti}=0.20)$ ARXPS provided a more detailed information than SEM with respect to the surface morphology of the samples.

\section{Conclusions}

From the above results, we can conclude that RBS, GDOES, and ARXPS are suitable and complementary techniques for in-depth and surface analysis of silver nanocluster segregation on $\mathrm{Ag}-\mathrm{TiCN}$ coatings down to the nanometer level.

The depth profile analysis obtained by RBS for the samples with higher Ag content revealed that the Ag was not uniformly distributed along the coating thickness, being found that a top surface layer was formed, followed by a depletion zone both 
for the samples deposited at RT and $200{ }^{\circ} \mathrm{C}$, respectively. GDOES analysis were performed in the samples to obtain a more accurate depth resolution, confirming the RBS observation of the existence of a top surface rich in Ag followed by a depletion zone, for the coatings with higher silver contents independent of the deposition temperature. The silver top layer was estimated to be of 1 and $22 \mathrm{~nm}$ for samples deposited at room temperature and at $200{ }^{\circ} \mathrm{C}$, respectively. The depletion zone was measured to be of 5 (room temperature) and $30 \mathrm{~nm}\left(200{ }^{\circ} \mathrm{C}\right)$. GDOES depth profiles also found a similar behavior for coatings deposited at $200{ }^{\circ} \mathrm{C}$ with lower silver content measuring the formation of an Ag-rich layer with a thickness of $3 \mathrm{~nm}$ and $18 \mathrm{~nm}$, for coatings with $\mathrm{Ag} / \mathrm{Ti}$ ratio of 0.20 and 0.40 GDOES analysis, respectively. Accordingly, the depletion zone depth was enhanced for higher Ag contents. The results obtained indicated that only the sample deposited at room temperature with the highest $\mathrm{Ag}$ content and those deposited at $200{ }^{\circ} \mathrm{C}$ showed the formation of an Ag-rich surface layer below which an Ag depletion zone of a few nanometers was formed. These observations were corroborated by ARXPS experiments and the subsequent modeling applying a general algorithm involving regularization to obtain the concentration depth profiles. This is attributed to the coalescence of Ag particles near the surface at the end of deposition process, which causes the growth of the $\mathrm{Ag}$ particles sited on the surface. As the surface particles grow at expense of the $\mathrm{Ag}$ clusters below the first nanometers under the surface, this creates a non-uniform Ag distribution in the first nanometers. Since the coalescence of Ag particles is due to the diffusion process, which is activated by the temperature, it was somehow expectable that the increase in the deposition

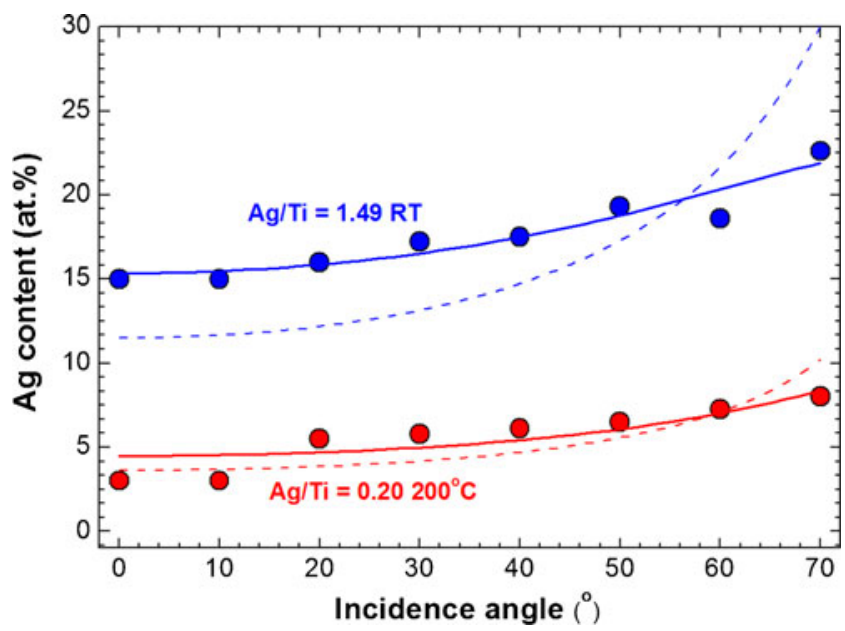

Fig. 8 Results of the parametric fitting of ARXPS data for samples $\mathrm{Ag} / \mathrm{Ti}=0.20\left(200{ }^{\circ} \mathrm{C}\right)$ and $\mathrm{Ag} / \mathrm{Ti}=1.49(\mathrm{RT})($ closed circles $)$. The dashed lines correspond to the best fit obtained using a step-like model while continuous lines correspond to the best fit using an island model
Table 3 Results of the best-fit parameters islands (height $d$ and coverage $\theta$ ), obtained from parametric modeling of the ARXPS data

\begin{tabular}{lll}
\hline Sample & Film thickness $d(\mathrm{~nm})$ & Coverage $\theta$ \\
\hline $\mathrm{Ag} / \mathrm{Ti}=1.49 \mathrm{RT}$ & 1.5 & 0.23 \\
$\mathrm{Ag} / \mathrm{Ti}=0.220{ }^{\circ} \mathrm{C}$ & 0.8 & 0.10 \\
\hline
\end{tabular}

temperature would promote the surface segregation. ARXPS measurements were used to provide further information on the surface morphology of the samples obtaining an excellent agreement with SEM observations when a growth model of silver islands with a height $d=1.5 \mathrm{~nm}$ and coverage $\theta=0.20$ was applied to the sample with $\mathrm{Ag} / \mathrm{Ti}=1.49$ and deposited at room temperature.

The production of Ag- TiCN coatings with small Ag clusters sited on the surface represents a promising structure for biomedical applications. However, it was found in previous studies that the presence of high Ag contents results in worse tribological performance. In this sense, coatings presented in this work with lower $\mathrm{Ag}$ content deposited at $200{ }^{\circ} \mathrm{C}$ represent a more challenging coating for antibacterial surfaces due to its higher surface area and, consequently, more likely to provide an enhanced silver ionization.

Acknowledgments This work was financially supported by the Spanish Ministry of Science and Innovation (projects FUNCOAT CSD2008-00023 and RyC2007-0026). This research is sponsored by FEDER funds through the program COMPETE "Programa Operacional Factores de Competitividade" and by national funds through FCT "Fundação para a Ciência e a Tecnologia", in the framework of the Strategic Projects PEST-C/FIS/UI607/2011, and PEST-C/ EME/UI0285/2011 and under the project PTDC/CTM/102853/2008. The authors would like to acknowledge I. Caretti and R. Velasco for the fruitful discussions and the proofreading of the manuscript.

\section{References}

1. Hauert R (2003) Diam Rel Mater 12:583-589

2. Escudeiro A et al (2013) Thin Solid Films. doi:10.1016/ j.tsf.2012.12.086

3. Liu C, Bi Q, Matthews A (2003) Surf Coat Technol 163-164:597_ 604

4. Serro AP et al (2009) Surf Coat Technol 203:3701-3707

5. Yildiz F, Yetimb AF, Alsaran A, Efeoglu I (2009) Wear 267:695701

6. Oliveira C, Gonçalves L, Almeida BG, Tavares CJ, Carvalho S, Vaz F, Escobar Galindo R, Henriques M, Susano M, Oliveira R (2008) Surf Coat Technol 203:490-494

7. Oliveira C, Escobar Galindo R, Palacio C, Calderon S, Almeida BG, Henriques M, Espinosa A, Carvalho S (2011) Solid State Sci 13:95-100

8. Sánchez-López JC, Abad MD, Carvalho I, Escobar Galindo R, Benito N, Ribeiro S, Henriques M, Cavaleiro A, Carvalho S (2012) Surf Coat Technol 206:2192-2198

9. Mulligan CP, Blanchet TA, Galla D (2010) Wear 269:125-13110 
10. Schierholz JM, Lucasj LJ, Rump A, Pulverer G (1998) J Hosp Infect 40:257-262

11. Kelly PJ, Li H, Benson PS, Whitehead KA, Verran J, Arnell RD, Iordanova I (2010) Surf Coat Technol 205:1606-16182

12. Morrison M, Buchanan R, Liaw P, Berry C, Brigmon R, Riester L, Abernathy H, Jin C, Narayan R (2006) Diam Rel Mater 15:138

13. Dowling DP, Betts AJ, Pope C, McConnell ML, Eloy R, Arnaud MN (2003) Surf Coat Technol 163-164:637-640

14. Hsieh JH, Tseng C, Chang YK, Chang SY, Wub W (2008) Surf Coat Technol 202:5586-5589

15. Cioffi N, Ditaranto N, Torsi L, Picca RA, Giglio E, Sabbatini L, Novello L, Tantillo G, Bleve-Zacheo T, Zambonin PG (2005) Anal Bioanal Chem 382:1912-191816

16. Li Q, Mahendra S, Lyon DY, Brunet L, Liga MV, Li D, Alvarez PJJ (2008) Water Res 42:4591-4602

17. Lok C, Ho CM, Chen R, He QY, Yu WY, Sun H, Tam PKH, Chiu JF, Che CM (2007) J Biol Inorg Chem 12:527-534

18. Morones J, Elechiguera JL, Cammacho A, Holt K, Kouri JB, Ramirez JT, Yacaman J (2005) Nanotechnol 16:2346-2353

19. Ferraris M, Perero S, Miola M, Ferraris S, Verné E, Morgiel J (2010) Mater Chem Phys 120:123-126

20. Escobar Galindo R, Gago R, Duday D, Palacio C (2010) Anal Bioanal Chem 396:2725-2740

21. Manninen NK et al (2011) J Phys D: Appl Phys 44:375501

22. Krzanowski JE, Endrino JL, Nainaparampil JJ, Zabinski JS (2004) J Mater Engin Perform 13(4):439

23. Adochite R, Munteanu D, Torrell M, Cunha L, Alves E, Barradas NP, Cavaleiro A, Riviere P, Bourhis E, Eyidi D, Vaz F (2012) Appl Surf Sci 258:4028-4034
24. Hu JJ, Muratore C, Voevodin AA (2007) Comp Sci Technol 67:336-347

25. Incerti L, Rotaa A, Valeri S, Miguel A, García JA, Rodríguez RJ, Osés J (2011) Vacuum 85:1108-1113

26. Clayton WB Jr, Chen QY (1995) Mater Lett 23:7-12

27. Climent-Font A, Pászti F, García G, Fernández-Jiménez MT, Agulló F (2004) Nucl Instrum Methods B 219:400-4

28. Kotai E (1994) Nucl Instrum Methods B 85:588-96

29. Mayer M (1997) SIMNRA User's Guide

30. Quentmeier A (1997) Sections 7.1 and 7.2. In: Payling R, Jones DG, Bengston A (eds) Glow discharge optical emission spectroscopy. Wiley, New York

31. Winchester R, Payling R (2004) Spectrochim. Acta Part B 59:607-666

32. Escobar Galindo R, Forniés E, Albella JM (2005) J Anal At Spectrom 20:1108-1115

33. Escobar Galindo R, Forniés E, Albella JM (2005) J Anal At Spectrom 20:1116-1120

34. Escobar Galindo R, Forniés E, Gago R, Albella JM (2007) J Anal At Spectrom 22:1512-1516

35. Arcos T, Oelhafen P, Aebi U, Hefti A, Duggelin M, Mathys D, Guggenheim R (2002) Vacuum 67:463-470

36. Niu F, Chang ITH, Dobson PJ, Cantor B (1997) Mater Sci Eng A226-228:161-167

37. Hofmann S (1991) Prog Surf Sci 36(1):35-87

38. CASA XPS software Ltd. v2.0 User's Manual www.casaxps.com. Accessed 10 January 2013

39. Palacio C, Ocón CP, Herrasti P, Díaz D, Arranz A (2003) J Electroanal Chem 545:53 